o

\title{
Advanced characterization of dissolved organic matter released by bloom-forming marine algae
}

\author{
Z.U. Rehman ${ }^{\mathrm{a}}$, S. Jeonga,*, S.A.A. Tabatabai ${ }^{\mathrm{a}}$, A.-H. Emwas ${ }^{\mathrm{b}}, \mathrm{T}$. Leiknes ${ }^{\mathrm{a}, *}$ \\ ${ }^{a}$ Water Desalination and Reuse Center (WDRC), Biological and Environmental Science E Engineering (BESE), \\ King Abdullah University of Science and Technology (KAUST), Thuwal 23955-6900, Saudi Arabia, \\ Tel. +966 12808 7504; email: Sanghyun.Jeong@kaust.edu.sa (S. Jeong); Tel. +966 12808 2193; \\ email:Torove.Leiknes@kaust.edu.sa (T. Leiknes); Tel.+966128080912; email: zahid.urrehman@kaust.edu.sa (Z.U. Rehman); \\ Tel.+966128082166; email: assiyeh.tabatabai@kaust.edu.sa (S.A.A. Tabatabai) \\ ${ }^{b}$ NMR Core Laboratory, 4700 King Abdullah University of Science and Technology (KAUST), Thuwal 23955-6900, Saudi Arabia, \\ email: abdelhamid.emwas@kaust.edu.sa
}

Received 20 April 2016; Accepted 24 June 2016

\begin{abstract}
A B S T R A C T
Algal organic matter (AOM), produced by marine phytoplankton during bloom periods, may adversely affect the performance of membrane processes in seawater desalination. The polysaccharide fraction of AOM has been related to (bio)fouling in micro-filtration and ultrafiltration, and reverse osmosis membranes. However, so far, the chemical structure of the polysaccharides released by bloom-forming algae is not well understood. In this study, dissolved fraction of AOM produced by three algal species (Chaetoceros affinis, Nitzschia epithemoides and Hymenomonas spp.) was characterized using liquid chromatography-organic carbon detection (LC-OCD) and fluorescence spectroscopy. Chemical structure of polysaccharides isolated from the AOM solutions at stationary phase was analyzed using proton nuclear magnetic resonance $\left({ }^{1} \mathrm{H}-\mathrm{NMR}\right)$. The results showed that production and composition of dissolved AOM varied depending on algal species and their growth stage. AOM was mainly composed of biopolymers (BP; i.e., polysaccharides and proteins [PN]), but some refractory substances were also present. ${ }^{1} \mathrm{H}-\mathrm{NMR}$ spectra confirmed the predominance of carbohydrates in all samples. Furthermore, similar fingerprints were observed for polysaccharides of two diatom species, which differed considerably from that of coccolithophores. Based on the findings of this study, ${ }^{1} \mathrm{H}-\mathrm{NMR}$ could be used as a method for analyzing chemical profiles of algal polysaccharides to enhance the understanding of their impact on membrane fouling.
\end{abstract}

Keywords: Algal organic matter; Marine algae; Membrane fouling; Nuclear magnetic resonance; Polysaccharides

\section{Introduction}

Algal organic matter $(\mathrm{AOM})$ represents an important component of natural organic matter (NOM) in surface waters. AOM comprises algal cells, extracellular organic matter $(\mathrm{EOM})$ and intracellular organic matter (IOM). EOM is released by the algal cells via diffusion and is

${ }^{*}$ Corresponding authors. typically produced in the exponential stage of cell growth while IOM is released as a result of cell death and lysis [1] Algae are known to produce AOM in response to stressful conditions such as low nutrient concentrations, absence of light, low $\mathrm{pH}$ and temperature [2], as well as under normal conditions [3].

AOM is mainly composed of polysaccharides (PS), nucleic acids, lipids, PN, amino acids and other organic acids. The relative proportions of these constituents may

Presented at the EDS conference on Desalination for the Environment: Clean Water and Energy, Rome, Italy, 22-26 May 2016. 
vary depending on species, age of culture and environmental conditions. The predominance of PS and PN in AOM results in its hydrophilic character $[1,4,5]$. Some species of algae produce high amounts of extracellular PS, which may constitute more than $80 \%$ of the overall AOM production [6]. These PS are highly sticky [7] and coagulate in the aquatic environment, causing formation of marine snow and sea foam [8].

In water treatment processes, $\mathrm{AOM}$ can pose a major problem due to water discoloration, release of taste and odor compounds, release of toxins, and production of carcinogenic disinfection byproducts (DBPs) $[9,10]$. From the perspective of seawater reverse osmosis (SWRO), algal blooms can adversely affect the operation of both pretreatment systems and reverse osmosis (RO) membranes [11-13]. AOM can strongly adhere to the surface or within the pores of micro-filtration and ultrafiltration (MF/UF) membranes in SWRO pretreatment causing irreversible fouling $[14,15]$. Furthermore, dissolved AOM is usually not retained by pretreatment and can initiate and/ or exacerbate particulate/organic fouling and biofouling in downstream RO membranes [16]. A number of studies have shown a correlation between the polysaccharide fraction of AOM and MF/UF membrane fouling [17-20]. Since AOM from different algae have different fouling potential and mechanisms $[21,22]$, it is important to analyze the structure and composition of algal PS released by different species for a better understanding of the interaction of these compounds with membrane surfaces. Using lectin staining and microscopy, it was found that AOM from different algal species contained different functional groups [21]. A subgroup of AOM known as transparent exopolymer particles (TEP) and their precursors are acidic PS and glycoproteins, which are highly sticky that may cause surface conditioning of $\mathrm{RO}$ membranes leading to biofilm formation [25].

Nuclear magnetic resonance (NMR) has been used to study the chemical composition of organic compounds released by bacteria and algae in seawater desalination and wastewater treatment applications [23-26]. NMR spectroscopy is a powerful analytical tool for identification, quantification and investigation of the chemical composition of carbohydrate compounds in the extracts of a given sample [27-30]. Moreover, a proton nuclear magnetic resonance $\left({ }^{1} \mathrm{H}-\mathrm{NMR}\right)$ spectroscopy is inherently a quantitative analytical method as the intensity of the NMR peak is proportional to the concentration of the H nuclei. Thus, NMR spectra are very useful for quantitative and comparative studies where the chemical shifts of NMR peaks are associated with different classes of molecules. To the best of our knowledge, a detailed characterization of the chemical structure of algal PS and compositional differences of these compounds among algal species has not been conducted.

In this study, dissolved AOM produced by three bloom-forming marine algae, a coccolithophore (Hymenomonas spp.: Hym) and two diatoms (Chaetoceros affinis and Nitzschia epithemoides), was selected. The patterns of algal growth and dissolved AOM production during the various growth stages were monitored. Detailed characteristics of dissolved AOM were investigated by advanced techniques such as liquid chromatography-organic carbon detection (LC-OCD) and florescence spectroscopy. The polysaccharide fraction isolated from $\mathrm{AOM}$ was further analyzed using ${ }^{1} \mathrm{H}-\mathrm{NMR}$.

\section{Materials and methods}

\subsection{Algae cultivation}

A bloom-forming coccolithopore species (Hym) provided by the Oceanological Observatory of Banyuls-sur-Mer and two bloom-forming marine diatom species (Chaetoceros affinis: CA, CCAP 1010/27, and Nitzschia epithemoides: NZ, CCAP 1052/18) obtained from the Culture Collection of Algae and Protozoa (Oban, Scotland) were selected. Hym is a marine coccolithopore that can cause blooms in nutrient-poor water in mild temperatures (typically during spring period). Hym cells are spherical in shape with calcareous cell walls. CA is a marine diatom species commonly found in temperate regions and known to form blooms in the early spring period, during which they release substantial amounts of extracellular polymeric substances [31]. CA cells are oval cylindrical in shape and range in size from 8 to $30 \mu \mathrm{m}$ with silicate cell walls [21]. $\mathrm{NZ}$ is a marine diatom species that is commonly associated with colder waters. NZ cells have a pennate structure and range in size from 7 to $30 \mu \mathrm{m}$ with silicate cell walls. Axenic cultures of each species were grown in duplicate in glass bottles filled with $2 \mathrm{~L}$ of seawater medium. The medium was prepared by filtering Red Sea water through $0.45 \mu \mathrm{m}$ cellulose acetate filter, followed by autoclaving at $121^{\circ} \mathrm{C}$ for 20 min and spiking with F/2 medium [32]. Silica was added to the culture medium $(\mathrm{F} / 2+\mathrm{Si})$ for the diatom species (i.e., $\mathrm{CA}$ and NZ). The algal cultures were incubated at $20^{\circ} \mathrm{C} \pm 2^{\circ} \mathrm{C}$ with continuous aeration and a 12/12 light/dark cycle for a period of $32 \mathrm{~d}$. Prior to use, all materials and glassware were sterilized by autoclaving. Samples were collected every $4 \mathrm{~d}$ during the culturing period for further analyses.

\subsection{Monitoring culture growth}

Growth of algal cultures was monitored by measuring chlorophyll-a (Chl-a) and cell density throughout the cultivation period. A modified Chl-a determination method [33] was used in accordance with the experimental conditions of this study. A $30-\mathrm{mL}$ sample volume drawn from the algal culture was vacuum filtered through a GF/C filter (Whatman, USA) at 0.5 bar. To extract Chl-a, the GF/C filter retaining the algal cells was placed in a $15 \mathrm{~mL}$ centrifuge tube with $10 \mathrm{~mL}$ of $90 \%$ acetone and stored at $4^{\circ} \mathrm{C}$ for $24 \mathrm{~h}$ wrapped in aluminum foil to block light. The sample was then centrifuged at $3,180 \mathrm{~g}$ for $10 \mathrm{~min}$. $2.5 \mathrm{~mL}$ of supernatant was taken to measure absorbance at 665,645 and $630 \mathrm{~nm}$ ( $90 \%$ acetone was used as blank). Chl-a concentration was calculated using the following equation:

Chl-a $(\mu \mathrm{g} / \mathrm{mL})=\frac{(11.6 \times \mathrm{E} 665-1.31 \times \mathrm{E} 645-0.14 \times \mathrm{E} 630 \times v}{V}$

where $v$ is acetone volume used for extraction $(\mathrm{mL}) ; V$ is filtered sample volume (mL); E665 is absorbance at $665 \mathrm{~nm}$; 
E645 is absorbance at $645 \mathrm{~nm}$ and E630 is absorbance at $630 \mathrm{~nm}$

Cell density was determined with a BD Accuri C6 flow cytometer (AnnArbor, MI). Samples were analyzed by excitation (Ex) at $488 \mathrm{~nm}$ from a blue solid-state laser. Auto-fluorescence from algae was measured in the FL3 channel for red fluorescence with the threshold set to 900 . Fluidics were set to 'medium' ( $35 \mu \mathrm{L} / \mathrm{min}$; core size $16 \mu \mathrm{m})$ and run limit was set to $50 \mu \mathrm{L}$. Sample volumes of $200 \mu \mathrm{L}$ were transferred to 96-well plates (white flat bottom) for measurement.

\subsection{AOM characterization}

Dissolved AOM produced by the algal species was characterized with LC-OCD and fluorescence spectroscopy for identification, quantification and fractionation of organic matter compounds. The bottle containing the culture was gently shaken to ensure homogeneity. Thereafter, a sample was drawn through a sampling port from the algal culture and filtered through a $0.45-\mu \mathrm{m}$ syringe filter prior to use in subsequent measurements.

LC-OCD (DOC-Labor, Germany), which utilizes a size exclusion chromatography (SEC) coupled with organic carbon and nitrogen detection, was used to fractionate and quantify AOM compounds based on their molecular weight. In the LC-OCD technique, sample is supplied by a mobile phase (phosphate buffer, $12.5 \mathrm{~g} \mathrm{KH}_{2} \mathrm{PO}_{4}$ [Fluka, USA] $+7.5 \mathrm{~g} \mathrm{Na}_{2} \mathrm{HPO}_{4} \times 2 \mathrm{H}_{2} \mathrm{O}$ [Fluka, USA] to $5 \mathrm{~L}$ ) at a flow rate of $1.5 \mathrm{~mL} / \mathrm{min}$ to the chromatographic column - a weak cation exchange column based on polymethacrylate. A dual column configuration was used in this study. Injection volume and retention time for all samples were 2,000 $\mu \mathrm{L}$ and $180 \mathrm{~min}$, respectively. Chromatograms were processed on the basis of area integration using a customized software program (ChromCALC). LC-OCD measurements were done in duplicate, and the mean value is reported (variation less than $5 \%$ ). The main fractions identified by the LC-OCD technique are BP, building blocks (BB), low molecular weight (LMW) acids and LMW neutrals. The definitions and molecular weight size ranges assigned to AOM fractions obtained from LC-OCD analyses are given by Huber et al. [34].

In the LC-OCD measurement, PN concentration in BP was estimated based on the concentration of organic nitrogen as detected by the organic nitrogen detector (OND) [35]. The C:N ratio of PN can be estimated as 3:1 assuming that all organic nitrogen in BP originates from PN. The BP fraction is composed of PS and PN, where $\mathrm{PN}=3 \times \mathrm{DON}$. Therefore, PS may be calculated following the equation: $\mathrm{BP}-(3 \times \mathrm{DON})$. A previous study [36] reported a good correlation of LC-OCD estimation with a direct assay.

A fluorescence spectrometer (FluoroMAX-4, Horiba, Japan) was used for fluorescence emission (Em) spectra of dissolved AOM samples. Fluorescence excitation emission matrix (FEEM) measurements were performed at an Ex wavelength ranging from 240 to $500 \mathrm{~nm}$ and an Em wavelength ranging from 290 to $600 \mathrm{~nm}$ simultaneously. The slit widths were set to $5 \mathrm{~nm}$ for both Ex and Em. Fluorescent organic matter exhibits different peaks at known Ex and Em wavelengths. Instrumental preferences were adjusted using the Ex spectra of $8 \mathrm{~g} / \mathrm{L}$ Rhodamine B solution (in ethylene
Table 1

Description of excitation emission matrix peaks

\begin{tabular}{|c|c|c|c|c|}
\hline Peak & Ex (nm) & $\operatorname{Em}(\mathrm{nm})$ & $\begin{array}{l}\text { Chemical } \\
\text { functionality }\end{array}$ & Category \\
\hline $\mathrm{A}$ & $250-260$ & $380-480$ & UV humic-like & Humic-like \\
\hline C & $330-350$ & $420-480$ & $\begin{array}{l}\text { Visible humic- } \\
\text { like }\end{array}$ & Fulvic-like \\
\hline M & $290-320$ & $380-420$ & $\begin{array}{l}\text { Visible marine } \\
\text { humic-like }\end{array}$ & \\
\hline B & $270-280$ & $300-310$ & $\begin{array}{l}\text { Tyrosine-like, } \\
\text { protein-like }\end{array}$ & Protein-like \\
\hline $\mathrm{T}$ & $270-280$ & $320-350$ & $\begin{array}{l}\text { Tryptophan- } \\
\text { like, protein- } \\
\text { like }\end{array}$ & \\
\hline
\end{tabular}

glycol) and Em spectra of a ground quartz diffuser (as recommended by the manufacturer). No changes in the lamp intensity during the measurement observed with comparison of the integrated Raman spectra of Milli-Q (MQ) water over Ex wavelengths $(\mathrm{Ex}=350 \mathrm{~nm})$. The fluorescence spectra were Raman calibrated by normalizing to the area under the Raman scatter peak (Ex $=350 \mathrm{~nm}$ ) of MQ water. The spectral data of EEM for the AOM compounds is given in Table 1.

\subsection{Structural analysis of polysaccharides}

PS were isolated from the algal cultures at the end of the cultivation period (day 32), for the identification of their chemical composition and structure. Cultures were centrifuged at 10,000 g, and the supernatant was filtered through GF/C glass fiber filters and subsequently by $0.45 \mu \mathrm{m}$ filter (Whatman, USA). The resulting dissolved AOM in solution was dialyzed against Milli-Q water for $4-5 \mathrm{~d}$ at $4^{\circ} \mathrm{C}$ using 3.5 kDa MWCO membranes (Spectrum Laboratories, USA). The dialyzed mixture was treated with trichloroacetic acid (Arcos, USA), with final concentration of $20 \%$, and incubated at room temperature for $30 \mathrm{~min}$ to precipitate $\mathrm{PN}$ and nucleic acids. To isolate the PS, the mixture was centrifuged at $16,800 \mathrm{~g}$ for $1 \mathrm{~h}$ at $4^{\circ} \mathrm{C}$, and the resulting supernatant was mixed with 1.5 times by volume of ice-cold ethanol (95\%) and placed at $-20^{\circ} \mathrm{C}$ for $24 \mathrm{~h}$ to remove lipids. This mixture was again centrifuged at $16,800 \mathrm{~g}$ for $1 \mathrm{~h}$ at room temperature, and the resulting exopolysaccharide pellet was re-suspended in distilled water and dialyzed against MilliQ water for $24 \mathrm{~h}$ at $4^{\circ} \mathrm{C}$ using $3.5 \mathrm{kDa}$ membranes. The dialyzed material was lyophilized for subsequent analysis [37].

Solution state ${ }^{1} \mathrm{H}-\mathrm{NMR}$ spectrometry was conducted to elucidate the structure of PS isolated from AOM produced by the three algal species. Samples were prepared by dissolving the lyophilized material in $600 \mu \mathrm{l}$ of deuterated water $\left(\mathrm{D}_{2} \mathrm{O}\right)$, of which $550 \mu \mathrm{l}$ was transferred to $5 \mathrm{~mm}$ NMR tubes. NMR spectra were acquired using a Bruker $700 \mathrm{MHz}$ AVANACIII NMR spectrometer equipped with Bruker CPTCI multinuclear CryoProbe (BrukerBioSpin, Rheinstetten, Germany). To achieve high signal to noise ratio, the ${ }^{1} \mathrm{H}-\mathrm{NMR}$ spectra were recorded by collecting $1 \mathrm{k}$ scans with a recycle delay time of $3 \mathrm{~s}$. To suppress the water peak, each spectrum was induced using an Ex sculpting pulse 
sequence through a standard (zgesgp) program from the Bruker pulse library. The temperature for all experiments was maintained at $298 \mathrm{~K}$. Chemical shifts were determined relative to 3-trimethylsilylpropane sulfonic acid (DSS, $20 \mu \mathrm{M}$ ), as internal chemical shift reference. The free induction decay (FID) data was collected with spectral width of $16 \mathrm{ppm}$ associated with $11261 \mathrm{~Hz}$ digitized into $64 \mathrm{k}$ data points. The FID signals were zero-filled and amplified by applying exponential line-broadening factor of $1 \mathrm{~Hz}$ prior to Fourier transformation. Bruker Topspin 2.1 software (Bruker BioSpin, Rheinstetten, Germany) was used to collect and analyze the data.

\section{Results and discussion}

\subsection{Algal growth pattern}

Growth curves of the three species, Hym, CA and NZ, were plotted based on Chl-a concentrations throughout the cultivation period of $32 \mathrm{~d}$ (Fig. 1). Three distinct growth phases, i.e., lag phase, exponential phase and stationary/ death phase, were observed for all algal species. The duration of the phases varied among species, as distinct growth patterns were observed. During exponential growth phase, cell density and Chl-a concentration continuously increased as cells multiplied due to availability of nutrients in the culture medium. After exhausting the available nutrients, the cultures entered into stationary/death phase marked by a stable or decreasing cell density and Chl-a concentration. As the stationary and death phases could not be clearly distinguished for all species, this period is designated as stationary/death period in this study.

A lag phase of $8 \mathrm{~d}$ was observed for Hym, after which Chl-a concentration increased exponentially until day 28 followed by the death phase. The difference in the length

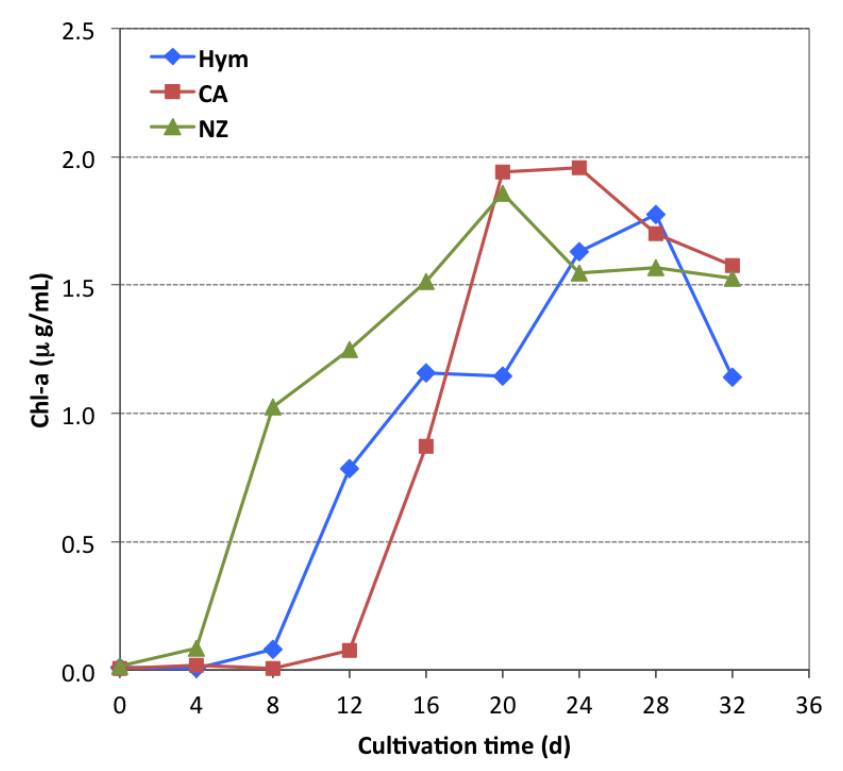

Fig. 1. Growth curves of three marine algal species (Hym, CA and NZ) in terms of Chl-a concentrations during the cultivation period. of lag phase for Hym in this and a recent study may be attributed to the age of the inoculum [22]. For CA, a lag phase of $12 \mathrm{~d}$ was observed, followed by a relatively short exponential growth phase, after which the stationary/ death phase began at day 20 . This growth pattern is consistent with the observations of Villacorte et al. [21]. NZ had the shortest lag phase of $4 \mathrm{~d}$ followed by an exponential phase of $16 \mathrm{~d}$, entering the stationary/death phase at approximately $20 \mathrm{~d}$ after inoculation. The earlier onset of the stationary/death phase for the two diatom species compared with the coccolithophore species may be due to the depletion of silica in the medium.

Growth curves established based on cell density showed a similar pattern to those based on Chl-a concentration for all species. For example, the maximum cell numbers monitored during the incubation were $8.9 \mathrm{E}+05,2.3 \mathrm{E}+06$ and $2.8 \mathrm{E}+06$ cells $/ \mathrm{mL}$ for Hym, CA and NZ, respectively. Based on the growth patterns, AOM production is discussed for (i) lag phase (day 4 of cultivation period); (ii) exponential phase (day 16 of cultivation period) and (iii) stationary/ death phase (day 28 of cultivation period).

\subsection{AOM characterization}

\subsubsection{Overall $A O M$ production}

Dissolved AOM production was monitored by LC-OCD analyses for quantification and fractionation of DOC at different growth stages. OCD chromatograms are presented for day 0 (inoculation), day 4, day 16 and day 28 (lag phase, exponential growth phase and stationary/death phase, respectively) of the cultivation period (Fig. 2). The chromatograms showed distinct peaks for BP (retention time 42-45 min), BB (retention time 66-69 min), LMW acids (retention time 72-75 $\mathrm{min}$ ) and LMW neutrals (retention time $>81 \mathrm{~min}$ ). Table 2 presents dissolved AOM concentrations in terms of DOC and DOC fractions produced by the algal species at different growth phases.

Dissolved AOM can be divided into high molecular weight (HMW)-AOM, comprising BP and LMW-AOM, comprising BB, LMW acids and LMW neutrals (Fig. 2 and Table 2). Consistent with other studies $[21,22,38]$, AOM production increased mainly due to increase in BP concentration during the cultivation period. For all three species, DOC concentration decreased from day 0 to day 4 (lag phase), as the concentration of LMW acids and neutrals decreased $(24 \%, 42 \%$ and $64 \%$ for Hym, CA and NZ, respectively). Compared with day 0 , no considerable difference was observed in BP and BB concentration during the lag period (day 4), while LMW organics (acids and neutrals) were significantly lower. The high uptake rate of LMW acids and neutrals by NZ during the initial $4 \mathrm{~d}$ might explain the short lag phase observed for this species. During the exponential growth and stationary/death phase, DOC concentration consistently increased for all three species, mainly due to increase in concentration of BP and BB; 4.3-5.4 times and 1.2-1.5 times, respectively, from day 4 to day 16 . This indicates that algae produce mainly BP and BB during their exponential growth period. Increase in LMW acids and neutrals during stationary/death phase (day 28) might be an indication of cell death/lysis and release of IOM, cell fragments and other debris $[39,40]$. 

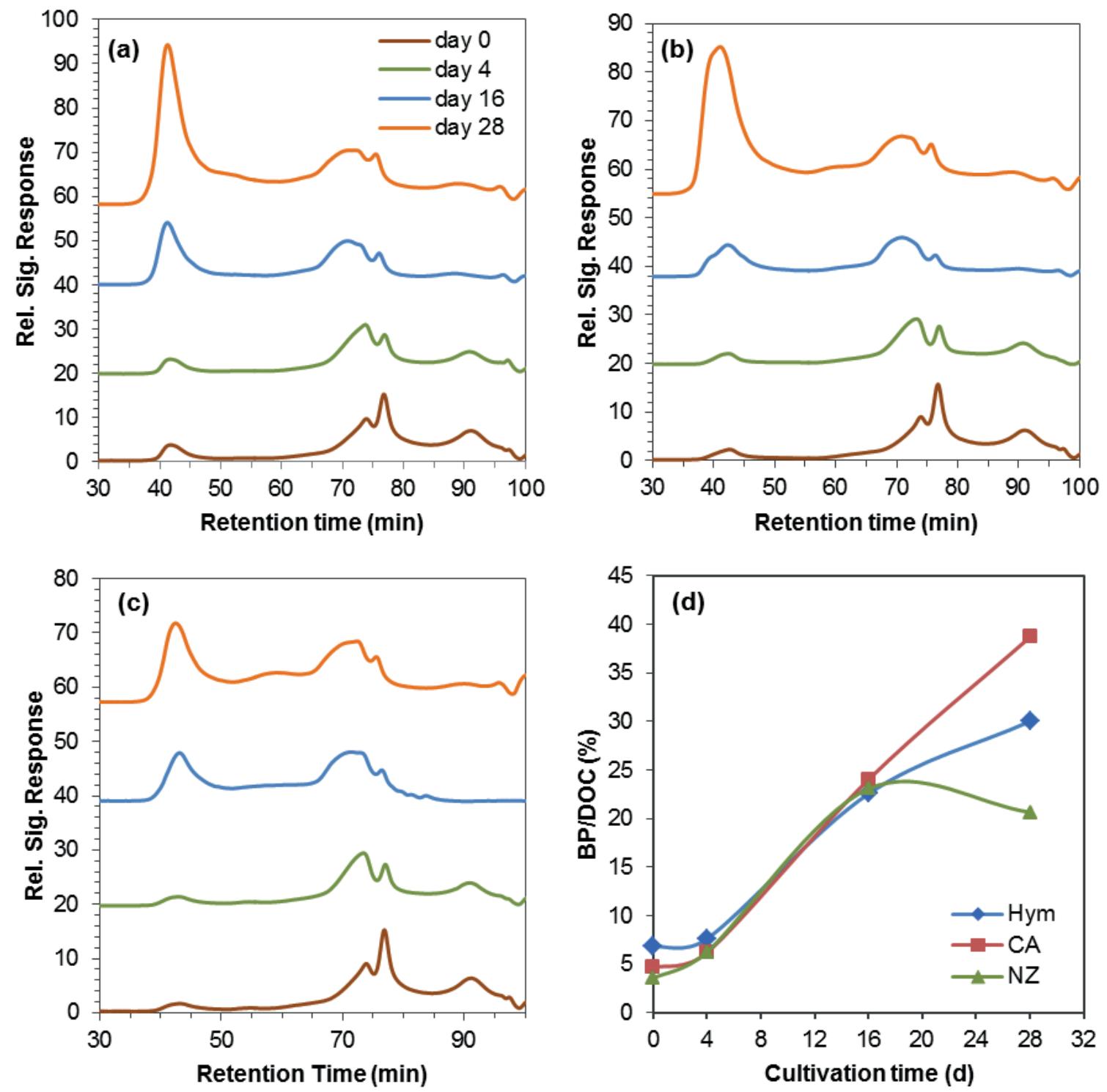

Fig. 2. OCD chromatograms of (a) Hym, (b) CA and (c) NZ at different growth phases (day $0=$ inoculation, day $4=$ lag phase, day 16 = exponential phase, and day 28 = stationary/death phase), and (d) ratio of biopolymers to DOC throughout the cultivation period. Offsets in chromatograms were made to enhance visual presentation. Retention times for peak maxima were observed at 42-45 min for biopolymers, 66-69 min for building blocks, 72-75 min for LMW acids, and >81 min for LMW neutrals.

The relative concentration of BP to overall DOC was plotted over time for the three species (Fig. 2(d)). The contribution of BP to overall DOC concentration was very similar for all three species during the inoculation period, lag phase and exponential growth phase. At stationary/death phase, CA had the highest ratio of BP to DOC, followed by Hym and NZ (40\%, 30\% and 20\%, respectively). Similar ratios were reported for Hym and CA in the literatures [22,41].

\subsubsection{Biopolymer production}

As observed from LC-OCD analyses (Fig. 2 and Table 2), $\mathrm{BP}$ production increased significantly throughout the cultivation period for all species, mainly due to increase in pro- duction of PS. During the stationary/death phase (day 28), $8.16 \mathrm{mg} \mathrm{C} / \mathrm{L}$ of BP was measured for Hym, as opposed to 8.06 and $6.10 \mathrm{mg} \mathrm{C} / \mathrm{L}$ for CA and NZ, respectively. BP concentration increased by $160 \%, 360 \%$ and $68 \%$ from exponential growth to stationary/death phase for Hym, CA and NZ, respectively. The amount of PS and PN in the BP fraction was calculated based on the concentration of organic nitrogen measured by the OND as mentioned in section 2.3. Concentrations of PS and PN calculated from LC-OCDOND results and PS:PN ratio are presented in Table 2 and Fig. 3.

BP produced by all algal species are mainly composed of PS (Fig. 3). Although BP production (including PS) increased throughout the cultivation period for all algal 
Table 2

Changes in concentration of DOC and AOM fractions at different algal growth phases (day $0=$ inoculation, day $4=$ lag phase, day $16=$ exponential growth phase, and day $28=$ stationary/death phase)

\begin{tabular}{|c|c|c|c|c|c|c|c|c|c|}
\hline \multirow[t]{2}{*}{ Species } & \multirow[t]{2}{*}{ Day } & \multirow{2}{*}{$\begin{array}{l}\mathrm{AOM} \\
\mathrm{DOC} \\
(\mathrm{mg} / \mathrm{L})\end{array}$} & \multicolumn{4}{|c|}{ HMW-AOM } & \multicolumn{3}{|c|}{ LMW-AOM } \\
\hline & & & $\begin{array}{l}\mathrm{BP} \\
(\mathrm{mg} \mathrm{C} / \mathrm{L})\end{array}$ & $\begin{array}{l}\text { PS } \\
(\mathrm{mg} \mathrm{C} / \mathrm{L})\end{array}$ & $\begin{array}{l}\mathrm{PN} \\
(\mathrm{mg} \mathrm{C} / \mathrm{L})\end{array}$ & PS:PN & $\begin{array}{l}\mathrm{BB} \\
(\mathrm{mg} \mathrm{C} / \mathrm{L})\end{array}$ & $\begin{array}{l}\text { LMW } \\
\text { acids } \\
(\mathrm{mg} \mathrm{C} / \mathrm{L})\end{array}$ & $\begin{array}{l}\text { LMW } \\
\text { neutrals } \\
(\mathrm{mg} \mathrm{C} / \mathrm{L})\end{array}$ \\
\hline \multirow[t]{4}{*}{ Hym } & 0 & 3.37 & 0.23 & 0.22 & 0.01 & 22 & 1.38 & 1.53 & 0.24 \\
\hline & 4 & 2.89 & 0.22 & 0.21 & 0.01 & 21 & 1.43 & 1.17 & 0.08 \\
\hline & 16 & 4.21 & 0.95 & 0.83 & 0.12 & 7 & 2.13 & 1.07 & 0.06 \\
\hline & 28 & 8.16 & 2.45 & 2.16 & 0.29 & 7 & 3.84 & 1.79 & 0.08 \\
\hline \multirow[t]{4}{*}{ CA } & 0 & 3.21 & 0.15 & 0.13 & 0.02 & 7 & 1.24 & 1.59 & 0.23 \\
\hline & 4 & 2.42 & 0.15 & 0.13 & 0.02 & 7 & 1.24 & 0.93 & 0.10 \\
\hline & 16 & 2.83 & 0.68 & 0.51 & 0.17 & 3 & 1.48 & 0.63 & 0.03 \\
\hline & 28 & 8.06 & 3.12 & 2.81 & 0.31 & 9 & 3.32 & 1.54 & 0.08 \\
\hline \multirow[t]{4}{*}{ NZ } & 0 & 3.64 & 0.13 & 0.09 & 0.03 & 3 & 1.32 & 1.96 & 0.24 \\
\hline & 4 & 2.24 & 0.14 & 0.11 & 0.03 & 4 & 1.31 & 0.71 & 0.08 \\
\hline & 16 & 3.25 & 0.75 & 0.43 & 0.32 & 1 & 1.91 & 0.72 & 0.05 \\
\hline & 28 & 6.10 & 1.26 & 0.78 & 0.48 & 2 & 2.91 & 1.88 & 0.05 \\
\hline
\end{tabular}

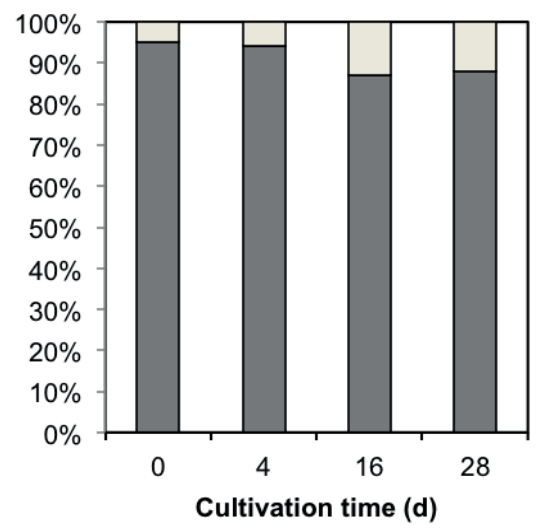

(a)

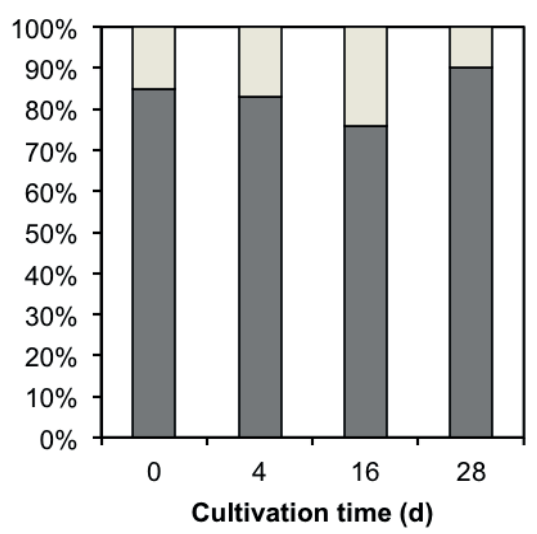

(b)

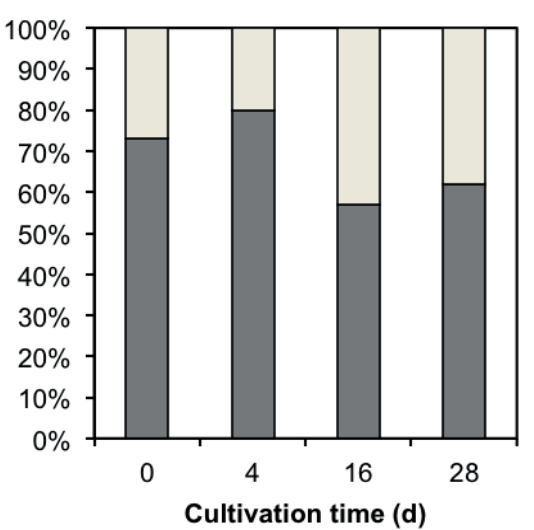

(c)

Fig. 3. Ratio of polysaccharides to proteins (PS:PN) in biopolymers produced by three marine algal species (a) Hym, (b) CA and (c) NZ during different stages of the growth cycle (day $0=$ inoculation, day $4=$ lag phase, day $16=$ exponential phase, and day 28 = stationary/death phase).

cultures (Table 2), the amount of BP, PS and PN, and the ratio between PS and $\mathrm{PN}$ varied among algal species. The increased concentration of $\mathrm{PN}$ in the stationary/death phase may be attributed to release of IOM during cell lysis or similar processes $[1,40]$.

For Hym, the PS fraction of BP was more than $85 \%$ during the entire cultivation period, which was higher than that of the other algal species (Fig. 3(a)). On day 16 and day 28, the PS:PN ratio was constant at around 7 . The amount of PN produced by Hym was about $6 \%, 13 \%$ and $12 \%$ of the BP concentration at day 4 , day 16 and day 28 of algal growth, respectively.

CA produced the largest amount of BP during stationary/death phase among the species studied (Fig. 3(b)). PS comprised approximately $80 \%$ of the BP throughout the cul- tivation period. Similar composition of BP was also observed in a recent study [21]. A PS:PN ratio of approximately 9 was observed on day 28 , against a ratio of 3 on day 16 . Diatoms of the genus Chaetoceros are known to produce large quantities of extracellular PS throughout their growth cycle [6,42].

NZ produced consistently lower amounts of PS and higher amounts of PN as compared with CA and Hym (Table 2). PN made $20 \%, 43 \%$ and $38 \%$ of the BP fraction produced by NZ on day 4, day 16 and day 28 of growth, respectively (Fig. 3(c)). The increased production of PN on day 16 suggests that NZ may secrete extracellular PN during exponential growth. The PS:PN ratio for NZ was lower than that of Hym and CA (Fig. 3).

The different amounts of PS and PN produced by different algal species suggest that they may have different 
fouling and biofouling mechanisms. There is a need of more detailed analysis of fouling mechanisms of individual algal species to better understand the role of dissolved AOM in membrane fouling.

\subsubsection{Fluorescent fractions of $A O M$}

The fluorescent fractions (PN-like, P; fulvic-like, F; and humic-like, $\mathrm{H}$ ) of AOM produced by the three algal species were analyzed by fluorescence spectroscopy. The analysis was performed on AOM solutions prefiltered through $0.45 \mu \mathrm{m}$ filters, i.e., dissolved AOM fractions. FEEM enables

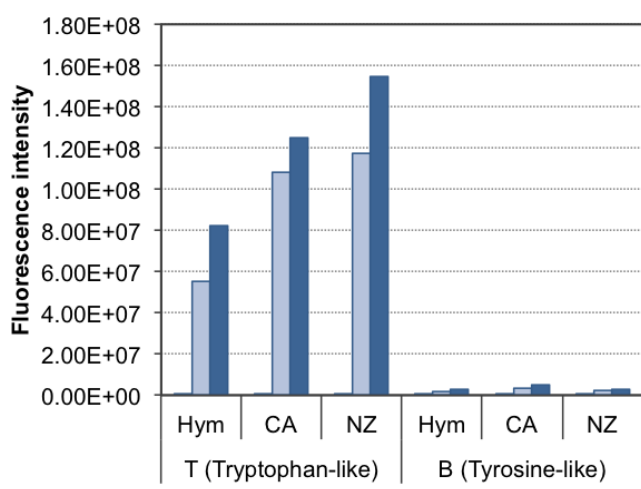

घay 4

Day 16

Day 28

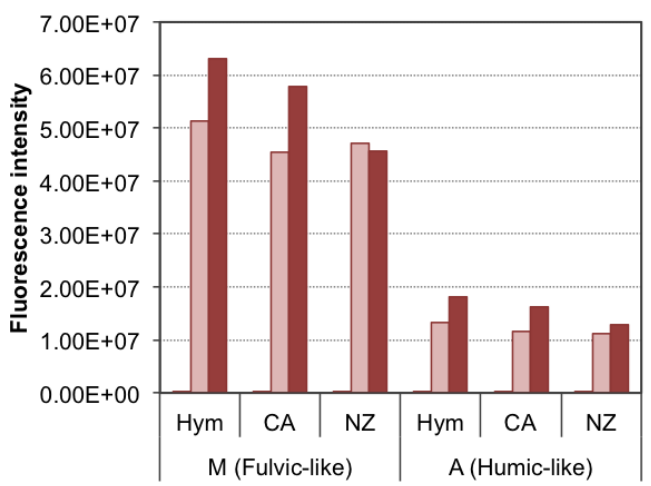

(b)

ロDay 4

口Day 16

Day 28

$\square \mathrm{M}($ Fulvic-like) $\quad \square \mathrm{A}($ Humic-like)

(c)

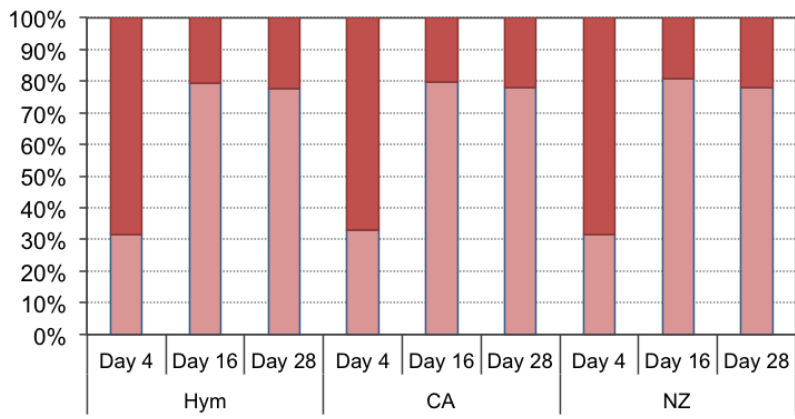

Fig. 4. Detailed fractions of fluorescent AOM: (a) tryptophan-like (T) and tyrosine-like (B), (b) fulvic-like (M) and humic-like (A), and (c) changes in ratio of fulvic-like (M) to humic-like (A) AOM obtained from axenic cultures of Hym, CA and NZ at different growth phases (day 4: lag phase, day 16: exponential phase, and day 28: stationary/death phase). in-depth analysis of the composition of PN and humic-/ fulvic-like compounds of dissolved AOM. Five characteristic peaks were observed: two PN-like peaks T and B, and three humic-like peaks A, M, and C (Table 1). PN-like (P) peaks (peaks $\mathrm{T}$ and $\mathrm{B}$ ) represent materials containing tryptophan-like (alpha-amino acid used in PN biosynthesis) and tyrosine-like (4-hydroxyphenylalanine used by cells to synthesize PN) compounds. Peaks A, M and C are indicative of humic-like compounds but peaks $\mathrm{M}$ and $\mathrm{C}$ have specifically been related to fulvic-like materials [43]. Hence, the sum of peaks $\mathrm{M}$ and $\mathrm{C}$ is considered as fulvic. In this study, however, visible humic-like compounds (C) were not considered since the peak was observed at low fluorescence intensity. A similar observation was reported by a previous study [35].

As can be seen from Fig. 4(a), PN produced by marine algae was mainly composed of tryptophan-like compounds, likely to have originated from the metabolic products of algal activity [44]. The production of tryptophan-like and tyrosine-like PN increased throughout the cultivation period for all algal species. The highest production of tryptophan-like PN was observed for NZ, followed by CA and Hym. PN production by Hym was the lowest among the algal species investigated in this study. These observations further confirm results from LC-OCD analyses in terms of PN production by the three species.

Hym had a higher production of humic-/fulvic-like compounds, as compared with CA and NZ (Fig. 4(b)). It can be clearly found in 3D-FEEM contour graphs of dissolved AOM produced from three algal species at day 28 (see the supporting information, Fig. S1). From LC-OCD analyses, Hym was found to produce more LMW-AOM (i.e., BB and LMW acids) during the cultivation period than CA and NZ (Table 2). This may indicate that LMW-AOM produced by marine algae is closely related with fulvic-like material from FEEM analysis. Interestingly, A (humic-like material) was higher than $\mathrm{M}$ (fulvic-like material) at day 4 (lag phase) for all algal species while the ratio of $\mathrm{M}$ (fulvic-like) to A (humic-like) increased up to around $80 \%$ at day 16 and day 28 (during exponential and stationary/death phases) (Fig. 4(c)).

In general, the fluorescence intensity of PN-like peaks was observed to be higher than that of humic-/fulvic-like peaks for all algal species. The fluorescence spectra

Table 3

Characteristic ${ }^{1} \mathrm{H}$ chemical shift assignments of typical compounds

\begin{tabular}{ll}
\hline Type of compound & $\delta^{-1} \mathrm{H}(\mathrm{ppm})$ \\
\hline Aliphatics & $0.5-1.7$ \\
$\mathrm{COOH}$ & $1.7-3.3$ \\
Carbohydrates & $3.3-3.7$ \\
Sugar ring protons & $3.7-4.5$ \\
Anomeric (carbohydrates) & $4.9-5.7$ \\
Double bonds & $5.7-6.7$ \\
Aromatic amino acid side chains & $7.7-8.7$ \\
Amide in Peptides & $8.7-9.7$ \\
\hline
\end{tabular}


supported the results of LC-OCD analyses in terms of the presence of PN and LMW compounds in dissolved AOM produced by the algal species.

\subsection{Chemical structure of PS in AOM}

${ }^{1} \mathrm{H}-\mathrm{NMR}$ spectra at $700 \mathrm{MHz}$ for algal PS obtained from Hym, CA and NZ are presented in Fig. 5. In biological samples, peaks observed at 0.8-1.1 ppm are usually associated with methyl groups of amino acids in peptides and $\mathrm{PN}$; peaks observed between 0.8 and $2.3 \mathrm{ppm}$ are usually associated to $\mathrm{CH}_{3}$ and $\mathrm{CH}_{2}$ in organic molecules; peaks between 2.2 and 5.2 ppm are generally carbohydrates (mainly sugar and PS); amide peaks are usually between 5.5 and $6.6 \mathrm{ppm}$; aromatic peaks are between 7 and $8.4 \mathrm{ppm}$; and peaks down the field at $8-10 \mathrm{ppm}$ are related to aldehydes $[25,44,45] .{ }^{1} \mathrm{H}$ chemicals shifts associated with different compounds are given in Table 3. All samples exhibited clear signals for carbohydrates related to sugars and PS within the 3.2-4.4 ppm chemical shift. Substantial differences were observed in the composition and structure of PS produced by the coccolithophore (Hym) and those produced by the diatom (CA and NZ) species. The chemical composition of Hym was more diverse than CA and NZ with notable signals around $1 \mathrm{ppm}$ in which typically PN and peptides methyl groups are observed. Interestingly, CA and NZ algae strains produced one type of extracellular polymeric substance. Although the NMR spectra of CA and NZ are quite similar compared with Hym, the comparison between the two spectra shows clear differences (Fig. 5).

Chemical shift assignment and interpretation of different peaks are presented in Fig. 6. This analysis was carried out based on the data published by Simpson et al. [44]. To investigate the composition of the PS, each NMR chemical shift assignment in the spectra was integrated and compared with one specific chemical shift assignment as reference. Aliphatic compounds within the 0.5-1.7 ppm chemical shift were used as reference in the integration. Relative integration values of other chemical shift assignments were determined by comparing their integration area with the reference. Total area of all assignments was summed, and the percentage of each assignment was calculated.
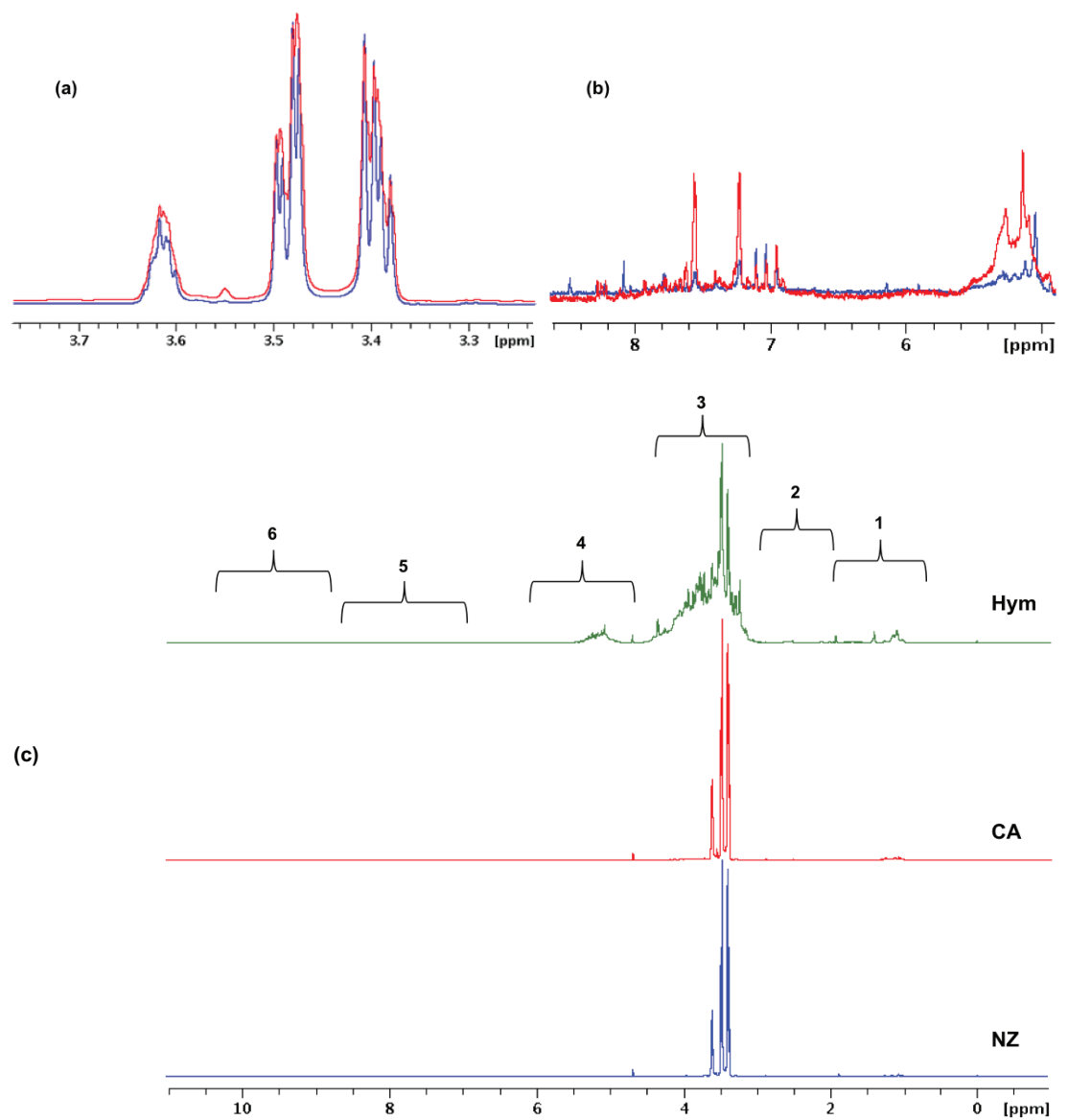

(c)

Fig. 5. $700 \mathrm{MHz}{ }^{1} \mathrm{H}$ NMR stack plot spectra of polysaccharides obtained from the marine diatom species CA (red) and NZ (blue) where (a) shows the extended region of spectra from 3.2 to $3.76 \mathrm{ppm}$, and (b) shows the extended region from 4.9 to 8.6 ppm, and (c) shows polysaccharides isolated from Hym, CA, and NZ, where (1) represents the typical aliphatic region, (2) represents carboxylic rich alicyclic molecules, (3) carbohydrates, mainly sugar and polysaccharides, (4) carbohydrates attached to electronegative atoms such as $\mathrm{O}$, halides, i.e., $\mathrm{O}-\mathrm{CH}_{\mathrm{n}^{\prime}}(5)$ aromatic, poly-aromatic and phenolic compounds and (6) typical aldehydes. 


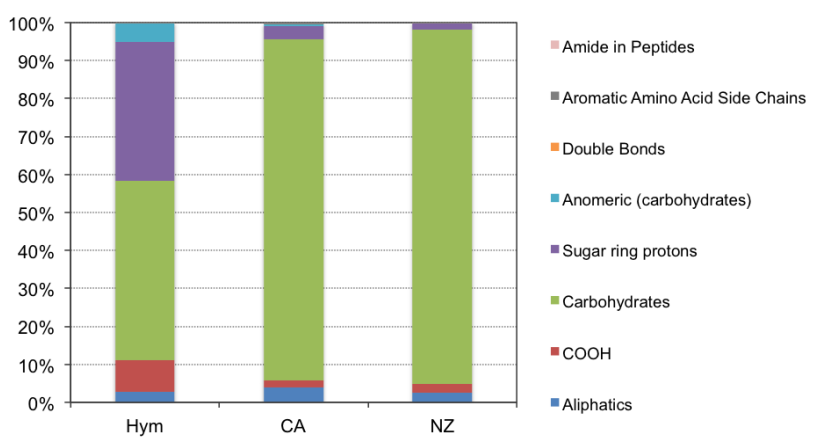

Fig. 6. Fraction assignment and integration of NMR spectra of polysaccharides obtained from Hym, CA and NZ.

A high concentration ratio of carbohydrate molecules was observed in CA and NZ samples. Very low concentration ratios of amide in peptides for all species indicate low PN content. This further confirms previous observations from LC-OCD and FEEM analyses. PS from CA and NZ contained a high proportion of $\mathrm{CH}_{2} \gamma$ to $\mathrm{COOH}$ compared with $\mathrm{Hym}$. While anomeric carbohydrates and $\beta$ to $\mathrm{COOH}$ were found in higher proportions in Hym compared with CA and NZ. These findings show that polysaccharide structure differs among various algal species that may lead to variations in fouling behavior and propensity. It further suggests that pretreatment for $\mathrm{RO}$ feed water and cleaning strategies should take into account the differences in chemical nature of PS and other components of dissolved AOM.

\section{Conclusions}

In this study, three marine algal species were cultivated, and their growth pattern and AOM production was characterized by LC-OCD and FEEM throughout the cultivation period. Algal PS were isolated/purified from the AOM and analyzed it by ${ }^{1} \mathrm{H}-\mathrm{NMR}$ to investigate the chemical structure of the PS and determine compositional differences among algal species. The main findings of the study are as follow:

- The three species showed different growth characteristics in terms of Chl-a concentration, cell density and AOM production. AOM production increased for all species throughout the cultivation period, mainly due to increase in BP concentration and BB.

- The BP fraction produced by the three algal species was mainly composed of PS. Although BP production increased throughout the cultivation period for all species, the amount of $\mathrm{BP}$, and the ratio between PS and PN varied among species. NZ produced consistently lower amounts of PS and higher amounts of PN as compared with CA and Hym.

- The fluorescence intensity of PN-like material was observed to be higher than that of humic-/fulvic-like material for all species. PN produced by marine algae were mainly composed of tryptophan-like compounds.

- The ${ }^{1} \mathrm{H}-\mathrm{NMR}$ fingerprint of the PS from the diatom strains was very similar and differed considerably from that of the coccolithophore species. ${ }^{1} \mathrm{H}-\mathrm{NMR}$ spectroscopy appears to be a powerful tool in identifying the structure/fingerprint of PS released from algae in sea- water matrices. Further studies should combine these results with membrane fouling studies to see whether PS with similar fingerprints result in comparable membrane fouling potential and mechanisms.

\section{Acknowledgment}

This study was supported by funding from King Abdullah University of Science and Technology (KAUST).

$\begin{array}{lll}\text { Abbreviations } & \\ \text { AOM } & - & \text { Algal organic matter } \\ \text { BB } & - & \text { Building blocks } \\ \text { BP } & - & \text { Biopolymers } \\ \text { CA } & - & \text { Chaetoceros affinis } \\ \text { Chl-a } & - & \text { Chlorophyll-a } \\ \text { DOC } & - & \text { Dissolved organic carbon } \\ \text { Em } & - & \text { Emission } \\ \text { EOM } & - & \text { Extracellular organic mater } \\ \text { EPS } & - & \text { Extracellular polymeric substances } \\ \text { Ex } & - & \text { Excitation } \\ \text { FEEM } & - & \text { Fluorescence excitation emission matrix } \\ \text { HMW } & - & \text { High molecular weight } \\ \text { Hym } & - & \text { Hymenomonas spp. } \\ \text { IOM } & - & \text { Intracellular organic matter } \\ \text { LC-OCD } & - & \text { Liquid chromatography-organic carbon } \\ & & \text { detection } \\ \text { LMW } & - & \text { Low molecular weight } \\ \text { MW } & - & \text { Molecular weight } \\ \text { NMR } & - & \text { nuclear magnetic resonance } \\ \text { NZ } & - & \text { Nitzschia epithemoides } \\ \text { PN } & - & \text { Proteins } \\ \text { PS } & - & \text { Polysaccharides } \\ \text { SEC } & - & \text { Size exclusion chromatography }\end{array}$

\section{References}

[1] M. Pivokonsky, O. Kloucek, L. Pivokonska, Evaluation of the production, composition and aluminum and iron complexation of algogenic organic matter, Water Res., 40 (2006) 3045-3052.

[2] S.M. Myklestad, Phytoplankton extracellular production and leakage with considerations on the polysaccharide accumulation, Annals Institute of Health, 35 (1999) 401-404.

[3] G.E. Fogg, The ecological significance of extracellular products of phytoplankton hotosynthesis, Botanica Marina, 26 (1983) 3-14.

[4] J. Fang, X. Yang, J. Ma, C. Shang, O. Zhao, Characterization of algal organic matter and formation of DBPs from chlor(am) ination, Water Res., 44 (2010) 5897-5906.

[5] N. Her, G. Amy, H.R. Park, M. Song, Characterizing algogenic organic matter (AOM) and evaluating associated NF membrane fouling, Water Res., 38 (2004) 1427-1438.

[6] S.M. Myklestad, Release of extracellular products by phytoplankton with special emphasis on polysaccharides, Sci. Total Environ., 165 (1995) 155-164.

[7] U. Passow, A.L. Alldredge, Distribution, size and bacterialcolonization of transparent exopolymer particles (TEP) in the ocean, Mar. Ecol. Prog. Ser., 113 (1994) 185-198.

[8] K. Mopper, J.A. Zhou, K.S. Ramana, U. Passow, H.G. Dam, D.T. Drapeau, The role of surface-active carbohydrates in the flocculation of a diatom bloom in a mesocosm, Deep Sea Res. Part II Top. Stud. Oceanogr., 42 (1995) 47-73. 
[9] L. Li, N. Gao, Y. Deng, J. Yao, K. Zhang, Characterization of intracellular \& extracellular algae organic matters (AOM) of Microcystic aeruginosa and formation of AOM-associated disinfection byproducts and odor \& taste compounds, Water Res., 46 (2012) 1233-1240.

[10] R. Gough, P.J. Holliman, G.M. Cooke, C. Freeman, Characterisation of algogenic organic matter during an algal bloom and its implications for trihalomethane formation, Sustain. Water Quality Ecol., (2015) 11-19.

[11] L.O. Villacorte, S.A.A. Tabatabai, D.M. Anderson, G.L. Amy, J.C. Schippers, M.D. Kennedy, Seawater reverse osmosis desalination and (harmful) algal blooms, Desalination, 360 (2015) 61-80.

[12] A. Berktay, Environmental approach and influence of red tide to desalination process in the middle east region, Int. J. Chem. Environ. Eng., 2 (2011) 183-188.

[13] T. Pankratz, Red Tides Close Desal Plants, Water Desalination Reports, Vol. 44, 2008.

[14] F.S. Qu, H. Liang, J.Y. Tian, H.R. Yu, Z.L. Chen, G.B. Li, Ultrafiltration (UF) membrane fouling caused by cyanobateria: fouling effects of cells and extracellular organics matter (EOM), Desalination, 293 (2012) 30-37.

[15] R. Schurer, A. Tabatabai, L. Villacorte, J.C. Schippers, M.D. Kennedy, Three years operational experience with ultrafiltration as SWRO pre-treatment during algal bloom, Desal. Wat. Treat., 51 (2013) 1034-1042.

[16] T. Berman, R. Mizrahi, C.G. Dosoretz, Transparent exopolymer particles (TEP): a critical factor in aquatic biofilm initiation and fouling on filtration membranes, Desalination, 276 (2011) 184-190.

[17] F. Qu, H. Liang, J. He, J. Ma, Z. Wang, H. Yu, G. Li, Characterization of dissolved extracellular organic matter $(\mathrm{dEOM})$ and bound extracellular organic matter (bEOM) of Microcystis aeruginosa and their impacts on UF membrane fouling, Water Res., 46 (2012) 2881-2890.

[18] L.O. Villacorte, Y. Ekowati, H. Winters, G. Amy, J.C. Schippers, M.D. Kennedy, MF/UF rejection and fouling potential of algal organic matter from bloom-forming marine and freshwater algae, Desalination, 367 (2015) 1-10.

[19] X.L. Zhang, L.H. Fan, F.A. Roddick, Influence of the characteristics of soluble algal organic matter released from Microcystis aeruginosa on the fouling of a ceramic microfiltration membrane, J. Membr. Sci., 425 (2013) 23-29.

[20] S.Q. Zhou, Y.S. Shao, N.Y. Gao, L. Li, J. Deng, C.Q. Tan, M.Q. Zhu, Influence of hydrophobic/hydrophilic fractions of extracellular organic matters of Microcystis aeruginosa on ultrafiltration membrane fouling, Sci. Total Environ., 470 (2014) 201-207.

[21] L.O. Villacorte, Y. Ekowati, T.R. Neu, J.M. Kleijn, H. Winters, G. Amy, J.C. Schippers, M.D. Kennedy, Characterisation of algal organic matter produced by bloom-forming marine and freshwater algae, Water Res., 73 (2015) 216-230.

[22] T. Merle, L. Dramas, L. Gutierrez, V. Garcia-Molina, J.P. Croue, Investigation of severe UF membrane fouling induced by three marine algal species, Water Res., 93 (2016) 10-19.

[23] M.T. Khan, M. Busch, V.G. Molina, A.-H. Emwas, C. Aubry, J.-P. Croue, How different is the composition of the fouling layer of wastewater reuse and seawater desalination $\mathrm{RO}$ membranes? Water Res., 59 (2014) 271-282.

[24] S. Li, H. Winters, S. Jeong, A.-H. Emwas, S. Vigneswaran, G.L. Amy, Marine bacterial transparent exopolymer particles (TEP) and TEP precursors: characterization and RO fouling potential, Desalination, 379 (2016) 68-74.

[25] S. Li, H. Winters, L.O. Villacorte, Y. Ekowati, A.-H. Emwas, M.D. Kennedy, G.L. Amy, Compositional similarities and differences between transparent exopolymer particles (TEPs) from two marine bacteria and two marine algae: significance to surface biofouling, Mar. Chem., 174 (2015) 131-140.

[26] G. Gonzalez-Gil, L. Thomas, A.-H. Emwas, P.N.L. Lens, P.E. Saikaly, NMR and MALDI-TOF MS based characterization of exopolysaccharides in anaerobic microbial aggregates from full-scale reactors, Sci. Rep., 5 (2015) 14316.
[27] A.L. Abuhijleh, H. Abu Ali, A.-H. Emwas, Synthesis, spectral and structural characterization of dinuclear rhodium (II) complexes of the anticonvulsant drug valproate with theophylline and caffeine, J. Organomet. Chem., 694 (2009) 3590-3596.

[28] A. Nageeb, A. Al-Tawashi, A.-H. Mohammad Emwas, Z. Abdel-Halim Al-Talla, N. Al-Rifai, Comparison of Artemisia апnи bioactivities between traditional medicine and chemical extracts, Curr. Bioact. Compd., 9(4) (2013) 324-332.

[29] E.G. Alves Filho, L.M. Alexandre e Silva, A.G. Ferreira, Advancements in waste water characterization through NMR spectroscopy: review, Magn. Reson. Chem., 53 (2015) 648-657.

[30] A. Loaiza, D. Borchardt, F. Zaera, A NMR method for the analysis of mixtures of alkanes with different deuterium substitutions, Spectrochim. Acta A Mol. Biomol. Spectrosc., 53 (1997) 2481-2493.

[31] S. Myklestad, A. Haug, Production of carbohydrates by the marine diatom Chaetoceros affinis var. willei (Gran) Hustedt. I. Effect of the concentration of nutrients in the culture medium, J. Exp. Mar. Biol. Ecol. 9(2) (1972) 125-136.

[32] R.R.L. Guillard, Culture of Marine Invertebrate Animals, 1975.

[33] O. Holm-Hansen, B. Riemann, Chlorophyll a determination: improvements in methodology, Oikos, 30 (1978) 438-447.

[34] S.A. Huber, A. Balz, M. Abert, W. Pronk, Characterisation of aquatic humic and non-humic matter with size-exclusion chromatography - organic carbon detection - organic nitrogen detection (LC-OCD-OND), Water Res., 45 (2011) 879-885.

[35] S. Jeong, S.J. Kim, C.M. Kim, S. Vigneswaran, T.V. Nguyen, H.K. Shon, J. Kandasamy, I.S. Kim, A detailed organic matter characterization of pretreated seawater using low pressure microfiltration hybrid systems, J. Membr. Sci., 428 (2013) 290-300.

[36] L.O. Villacorte, M.D. Kennedy, G.L. Amy, J.C. Schippers, The fate of transparent exopolymer particles (TEP) in integrated membrane systems: removal through pre-treatment processes and deposition on reverse osmosis membranes, Water Res., 43 (2009) 5039-5052.

[37] R.K. Henderson, A. Baker, S.A. Parsons, B. Jefferson, Characterisation of algogenic organic matter extracted from cyanobacteria, green algae and diatoms, Water Res., 42 (2008) 3435-3445.

[38] H. Konno, Settling and coagulation of slender type diatoms, Water Sci. Technol., 27 (1993) 231-240.

[39] M. Pivokonsky, J. Safarikova, M. Baresova, L. Pivokonska, I. Kopecka, A comparison of the character of algal extracellular versus cellular organic matter produced by cyanobacterium, diatom and green alga, Water Res., 51 (2014) 37-46.

[40] S.A.A. Tabatabai, J.C. Schippers, M.D. Kennedy, Effect of coagulation on fouling potential and removal of algal organic matter in ultrafiltration pretreatment to seawater reverse osmosis, Water Res. 59 (2014) 283-294.

[41] H.G. Dam, D.T. Drapeau, Coagulation efficiency, organic-matter glues and the dynamics of particles during a phytoplankton bloom in a mesocosm study, Deep Sea Res. Part II Top. Stud. Oceanogr., 42 (1995) 111-123.

[42] S. Jeong, G. Naidu, R. Vollprecht, T. Leiknes, S. Vigneswaran, In-depth analyses of organic matters in a full-scale seawater desalination plant and an autopsy of reverse osmosis membrane, Sep. Purif. Technol., 162 (2016) 171-179.

[43] S. Jeong, S.J. Kim, L.H. Kim, M.S. Shin, S. Vigneswaran, T.V. Nguyen, I.S. Kim, Foulant analysis of a reverse osmosis membrane used pretreated seawater, J. Membr. Sci., 428 (2013) 434-444.

[44] A.J. Simpson, D.J. McNally, M.J. Simpson, NMR spectroscopy in environmental research: from molecular interactions to global processes, Prog. Nucl. Magn. Reson. Spectrosc., 58 (2011) 97-175.

[45] A.-H.M. Emwas, R.M. Salek, J.L. Griffin, J. Merzaban, NMR-based metabolomics in human disease diagnosis: applications, limitations, and recommendations, Metabolomics, 9 (2013) 1048-1072. 


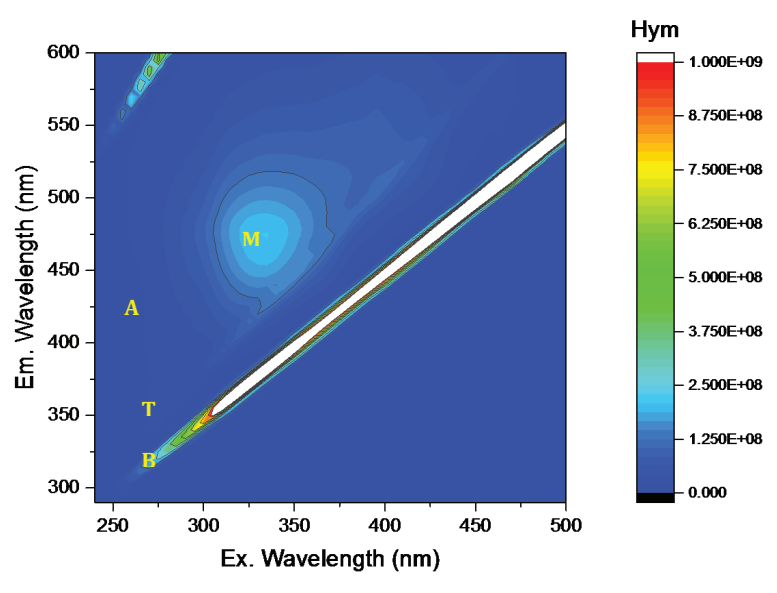

(a) Hym

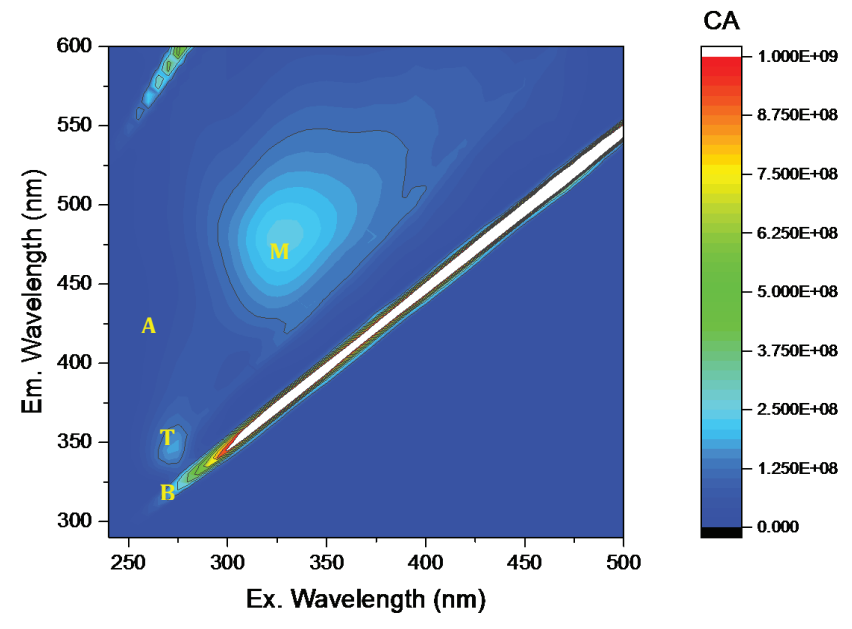

(b) $\mathrm{CA}$

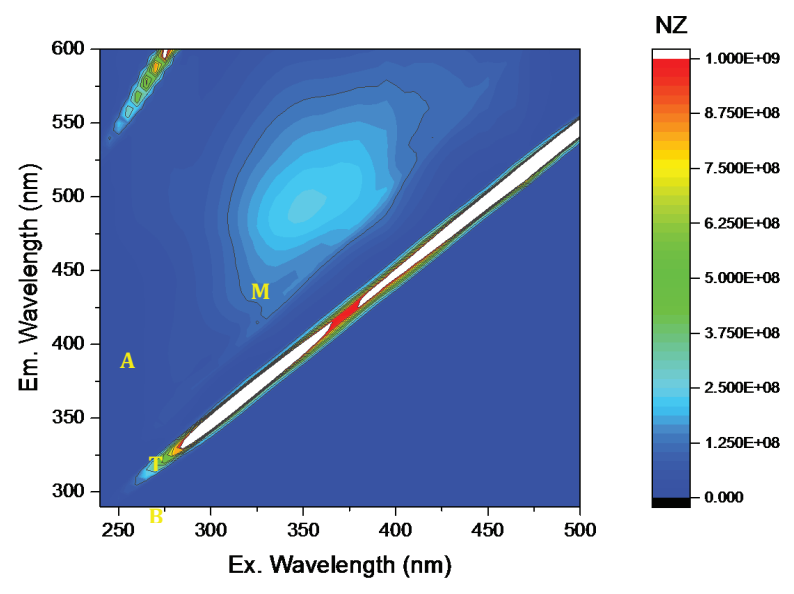

(c) NZ

Fig. S1. 3D-FEEM contour graphs of dissolved AOM produced from three different algal species at day 28 ((a) Hym, (b) CA, and (c) NZ) (T: tryptophan-like, B: tyrosine-like, M: fulvic-like, and A: humic-like). 